\title{
Growing fish and plants using aquaponic, hydroponic and mixed technologies
}

\author{
Aleksandr Kovrigin ${ }^{1}$, Grigorii Pokhodnya ${ }^{1}$, Yuriy Breslavets ${ }^{1,}{ }^{*}$, Alexander Breslavets ${ }^{1}$, and \\ Valerya Zhabinskaya ${ }^{2}$ \\ ${ }^{1}$ Belgorod State Agricultural Univerisity named after V. Gorin pos. Mayskiy, Russia \\ ${ }^{2}$ Administration of the Governor of the Belgorod Region Region, Sobornaya Square, 4, 308005 \\ Belgorod, Russian Federation
}

\begin{abstract}
Aquapon technology has a positive effect on the growth of live weight of Clary catfish per $1 \mathrm{~m} 3$ of the water environment in comparison with ultrasound. As a result, this indicator in the aquapon installation was higher by 456 grams or $1.1 \%$ for 45 days ompared to the USV. Profitability cleavage catfish in aquaponic operation installation was $22.8 \%$, which is $1.4 \%$ higher than the same indicator of RAS. The combined aquaponic-hydroponic mode of operation of the unit allowed to obtain $8.282 \mathrm{~kg}$ of vegetative mass of lettuce plants from $1 \mathrm{~m} 2$ of the installation area for 45 days, which is $2.761 \mathrm{~kg}$ more than in the traditional aquaponic mode and $0.903 \mathrm{~kg}$ more than in the hydroponic mode.
\end{abstract}

\section{Introduction}

Aquaponics is a technology for the production of crop and aquaculture products using their symbiotic interactions with each other and microorganisms to produce environmentally friendly products for human nutrition and animal feeding.

Aquaponics technologically includes at least two technologies - aquaculture and hydroponic.

Aquaculture is a technology for the production of various aquatic organisms (animals or plants) under human-controlled conditions, mainly for obtaining food or replenishing commercial stocks of aquatic biological resources.

Hydroponics is a technology for growing plants on artificial nutrient media. The soil is not used. At the same time, productivity increases and material costs for the production of a unit of production are reduced.

Aquaponic technology takes advantage of both hydroponics and aquaculture. Among the latter, technologies for the production of hydrobionts in recirculating installations with a closed water supply system are particularly relevant, since they allow saving such a valuable resource as water. Therefore, for aquaponics, it is advisable to use ultrasonic technologies as the basic ones. Aquaponic products are used to feed animals in order to increase their productivity $[2-9,11]$ and to feed humans with environmentally safe and relatively

\footnotetext{
*Corresponding author: umat_05@mail.ru
} 
inexpensive products that improve their productivity. metabolic processes in the body [1, 10].

With this technology, the use of pesticides is almost completely excluded. Instead, they use symbiotic relationships between animals, plants, and microorganisms in which these organisms protect each other from negative factors and promote mutual growth and development in man-made settings. At the same time, automation systems are used as much as possible, which maintain optimal conditions for the life of all symbionts [10, 12].

\section{Materials and methods}

Our aquaponic installation consisted of a USV for warm-water aquaculture and a separate plant module. UZV includes 8 tanks for growing fish in the amount of 1,600 kg per year, biological filters for growing symbiotic microflora, a drum-type mechanical filter, a system for ultraviolet disinfection of water, a water aeration system (to increase the oxygen content) and degassing to remove gaseous products of fish vital activity (carbon dioxide, etc.), automatic feeders. As an additional biological filter for the installation was the plant module is used. The module consists of a cabinet with transparent doors made of cellular polycarbonate, phytolamps, a drip irrigation system, a system for fixing the root system of plants without using soil (based on perlite), a system for supplying and removing water from the USV and a system for supplying nutrient solutions for plants. The equipment was controlled on the basis of a controller and software developed by the author.

Clary catfish, green mass of lettuce plants, and wheat grains were grown in an aquaponic plant.

Two experiments were conducted. The research scheme is shown in Table 1. The plant module was divided into three tiers for the experiment.

On the first tier, both water from the USV and a hydroponic nutrient solution were used for plant nutrition, on the second - water from the USV (foliar fertilization with mineral fertilizers and germination on a peat substrate were used), and on the third - only a hydroponic solution. Other growing conditions were the same for all plots and corresponded to the recommendations for growing green mass of lettuce of the Moscow Greenhouse variety.

A special mode of operation of the installation was developed to prevent the ingress of hydroponic solution residues into the USV.

Part of the closed water supply unit was connected to the plant growing unit. The other part of the USV functioned independently. In both parts of the USV, clary catfish was grown at a planting density of $120 \mathrm{~kg}$ per $1 \mathrm{~m} 3$ of water medium.

Clary catfish was grown under the same conditions in two independent parts of the USV, with the exception of additional biofiltration of water from one part of the USV by plants. To ensure this, water from one part of the USV had an additional circulation circle through the plant module.

Table 1. Scheme of the first experiment.

\begin{tabular}{|c|c|c|c|}
\hline Indicators & $\begin{array}{c}\text { The first section of } \\
\text { the comb installation }\end{array}$ & $\begin{array}{c}\text { The second section of } \\
\text { the aqua installation }\end{array}$ & $\begin{array}{c}\text { The third section of } \\
\text { the hydro }\end{array}$ \\
\hline $\begin{array}{c}\text { Operating mode of the } \\
\text { pump for supplying } \\
\text { water from the RAS }\end{array}$ & $\begin{array}{c}30 \text { minutes work, 4 } 5 \\
\text { minutes off }\end{array}$ & $\begin{array}{c}30 \text { minutes work, 15 } \\
\text { minutes off }\end{array}$ & disabled \\
\hline $\begin{array}{c}\text { Hydroponic nutrient } \\
\text { solution pump operating } \\
\text { mode }\end{array}$ & $\begin{array}{c}15 \text { minutes work, 60 } \\
\text { minutes off }\end{array}$ & disabled & $\begin{array}{c}30 \text { minutes work, 15 } \\
\text { minutes off }\end{array}$ \\
\hline
\end{tabular}




\begin{tabular}{|c|c|c|c|}
\hline $\begin{array}{c}\text { Duration of illumination } \\
\text { of plants, hours }\end{array}$ & 12 & 12 & 12 \\
\hline $\begin{array}{c}\text { Illumination intensity, } \\
\text { lux }\end{array}$ & 6000 & 6000 & 6000 \\
\hline Unit temperature, ${ }^{\circ} \mathrm{C}$ & $19-20$ & $19-20$ & $19-20$ \\
\hline $\begin{array}{c}\text { Duration of the } \\
\text { experiment, days }\end{array}$ & 45 & 45 & 45 \\
\hline
\end{tabular}

The following indicators were taken into account:

- hydrochemical indicators of experimental pools

- $\quad$ vegetative mass and commercial quality of plants;

- $\quad$ productivity of clary catfish in aquaponic and ultrasonic technologies;

- water consumption during the operation of an aquaponic installation in comparison with USV;

- cost-effective operation of the USV and aquapon installation.

The hydrochemical parameters of the experimental pools corresponded to technological standards.

\section{Results and Discussion}

However, with the aquaponic technology, the water in the USV was significantly lower in carbon dioxide, ammonia, nitrite and nitrate ions, water $\mathrm{pH}$, and more oxygen than in the classical USV technology. This contributed to an increase in the productivity of clary catfish.

Plant productivity is shown in Table 2 . When using a combined method of growing lettuce plants (alternating the use of hydroponic and aquaponic technology for 3 days), the best results were obtained. So, the weight of plants was higher by 40 and 15 grams in comparison with traditional aqua-and hydroponic technologies. This allowed us to get $8,282 \mathrm{~kg}$ of lettuce from $1 \mathrm{~m} 2$ of the plant module area. With aquaponic technology, 2,761 $\mathrm{kg}$ of lettuce was obtained less, and with hydroponic technology-0.903 kg less.

Table 2. Vegetative mass and commercial quality of aquapon salad.

\begin{tabular}{|l|c|c|c|}
\hline Indicators & $\begin{array}{l}\text { First installation } \\
\text { section }\end{array}$ & $\begin{array}{l}\text { Second installation } \\
\text { section }\end{array}$ & $\begin{array}{l}\text { Third installation } \\
\text { section }\end{array}$ \\
\hline $\begin{array}{l}\text { Average weight of one } \\
\text { salad plant on 45 days } \\
\text { of cultivation, g }\end{array}$ & $138 \pm 0.30$ & $98 \pm 0.32$ & $123 \pm 0.31$ \\
\hline $\begin{array}{l}\text { Number of plants per } \\
1 \mathrm{~m}^{2} \text { in a 3-tiered } \\
\text { installation, pcs. }\end{array}$ & 60 & 60 & 60 \\
\hline $\begin{array}{l}\text { Vegetative mass of } \\
\text { lettuce plants per 1 m } \\
\text { kg }\end{array}$ & $8.282 \pm 0.002$ & $5,521 \pm 0002$ & $7.379 \pm 0.002$ \\
\hline Commodity quality & high & the average & high \\
\hline
\end{tabular}

In the aquaponic installation, 456 grams more live weight gain of hydrobionts was obtained during 45 days than in the USV. This is due to the greater preservation of juvenile clary catfish in the aquaponic installation by $0.5 \%$. Increases in live weight of fish in the aquaponic part of the installation tended to increase. The water consumption in both parts of the installation did not significantly differ. However, in the aquaponic mode of operation, crop production was additionally obtained on this volume of water. 
The profitability of lettuce production was $116.9 \%$ with the combined aquaponichydroponic technology. The worst result in terms of weight, quality and economy is obtained with traditional aquaponic technology.

Thus, the profit from the sale of fish amounted to 738.94 rubles in UZ, which is 48.13 rubles or $6.1 \%$ less than in an aquaponic installation. The profitability of clary catfish production in the aquaponic mode of operation of the plant was $22.8 \%$, which is $1.4 \%$ higher than the same indicator of the USV operation.

Profit from the sale of plants using the combined technology was the maximum and amounted to 437.46 rubles per $1 \mathrm{~m} 2$ of plant module.

Thus, the combined aquaponic-hydroponic scheme for the production of lettuce and clary catfish plants turned out to be more cost-effective in comparison with USV and aquaponics.

The total profit from the sale of plant and fish products was in the combined aquaponichydroponic mode of operation of the plant. Thus, 879.92 rubles were produced per $1 \mathrm{~m} 3$ of water. This is $8.2 \%$ better than in other operating modes of the plant, which positively affected the overall profitability of operation, which increased by $1.9 \%$.

In the second experiment, wheat grains were sprouted on water from the USV. The scheme of the experiment is presented in Table 3.

Table 2. Scheme of the second experiment.

\begin{tabular}{|c|c|}
\hline Indicators & Germination of grain \\
\hline $\begin{array}{c}\text { Operating mode of the pump for supplying } \\
\text { water from the RAS }\end{array}$ & $\begin{array}{c}15 \text { minutes work, } \\
23 \text { hours } 45 \text { minutes disabled }\end{array}$ \\
\hline $\begin{array}{c}\text { Operating mode of the water supply pump to } \\
\text { the RAS }\end{array}$ & disabled \\
\hline $\begin{array}{c}\text { Operating mode of the pump for supplying } \\
\text { water to plants }\end{array}$ & $\begin{array}{c}15 \text { minutes work, } \\
3 \text { hour disabled }\end{array}$ \\
\hline Duration of illumination of plants, hours & 12 \\
\hline Illumination intensity, lux & 6000 \\
\hline Unit temperature, ${ }^{\circ} \mathrm{C}$ & 20 \\
\hline Duration of the experiment, days & 6 \\
\hline
\end{tabular}

At the same time, the grain was placed in the plant after preliminary preparation for four days according to the method developed by us using a drug that is our know-how. Instead of being directly discharged into the sewer, the water used in the RAS passed through a fourtiered plant module, feeding the germinated grain, and only after that, without returning to the RAS, was discharged into the sewer. Thus, the water consumption in the ultrasonic system did not change when operating in this mode in comparison with traditional technology and amounted to $0.48 \mathrm{~m} 3 /$ day. However, in addition to aquaculture products, plant products were obtained in the form of sprouted grain, the weight of which per $1 \mathrm{~m} 2$ of the plant was $18.2 \mathrm{~kg}$. The cost of sprouted grain was 32 RUB 80 kopecks or 1 RUB 80 kopecks per $1 \mathrm{~kg}$ of sprouted grain. The main share in the cost price was taken by the cost of the most sprouted grain $97.8 \%$. 


\section{Conclusion}

Based on the conducted studies, it was found that there were no significant differences in the hydrochemical parameters of the aquaponic installation and the USV, with the exception of a decrease in the level of carbon dioxide. However, in the aquaponic installation, there was a tendency to decrease the $\mathrm{pH}$ of the medium and the amount of nitrogenous compounds, as well as to increase the level of dissolved oxygen. As a result, the live weight gain of hydrobionts in the aquaponic installation was higher by 456 grams or $1.1 \%$ during 45 days compared to the USV. The profitability of clary catfish production in the aquapon mode of operation of the plant was as follows: $22.8 \%$, which is also $1.4 \%$ higher than the same indicator of the work of the USV.

In the course of research, it was found out that the cultivation of clary catfish using aquaponic and combined technologies with the use of plants as additional "biofilters" improves the hydrochemical parameters of water. This did not significantly affect the growth of fish, but increased their safety, especially in the early stages of development, which ultimately increased the fish productivity of aquaculture by $1.1 \%$ over 45 days of cultivation. With the full cycle of catfish cultivation, the profitability of production increased by $1.4 \%$ compared to the USV and amounted to $22.8 \%$.

The plant module of the aquaponic installation showed the best results in the combined mode of operation (aquaponic mode was replaced by hydroponic mode with a frequency of 1 time in 3 days). In this mode, $8,282 \mathrm{~kg}$ of lettuce plants were obtained per $1 \mathrm{~m} 2$ of module area. It is important that when receiving additional plant products, the water consumption in the USV did not change. That is, water was used that, with traditional technology, was simply drained into the sewer system as technical, although its quality made it possible to grow crop products.

Thus, this combined technology has shown greater efficiency both economically (by $3.5 \%$ ) and environmentally in comparison with USV. However, additional studies are required to identify the balance of plants, fish and symbiont microorganisms, as well as their species, breed and variety composition in this technology.

It is important to note that from the point of view of land use, germination of wheat grains in aquaponic water turned out to be the most effective. At the same time, with 1-2 m2 of installation area during the year, you can get the same amount of green mass as it is obtained in traditional agriculture from 1 ha of pasture area. The cost of labor and resources was insignificant. The main share in the cost price was taken by the cost of the most sprouted grain $97.8 \%$. This technology does not replace the cultivation of grain crops by traditional methods, but allows you to get good green animal feed in the cold season. This grain, when sprouted, acquires additional biological value and can be used as a source of active vitamins, phytoestrogens, and easily digestible nutrients in animal feeding.

\section{References}

1. S.A. Eriomin, O.N. Durykhina, "The use of computers to control the microclimate in poultry farms," Proceedings of the International student scientific conference, Belgorod: Publishing house of BelSAU, 80-81 (2008)

2. G.S. Pokhodnya, A.V. Kovrigin, A.M. Mamenko, Problems of Zooengineering and Veterinary Medicine, Kharkiv, 31-1, 164- 166, (2015)

3. N.N. Shvetsov, G.S. Pokhodnya, S.P. Salamakhin, Stock Farming of Russia, 10, 43-44 (2009)

4. O.N. Yastrebova, Feeding of farm animals, (Animal Science, Belgorod, Belgorod SAU, 2016) 
5. V.A. Panarina, O.N. Yastrebova, Cultivation of fish and plants with aquaponic technology, Gorin readings. Science of young - for innovative development of agriculture, Materials of the international student scientific conference, Belgorod, Belgorod SAU, 126-127 (2019)

6. A.V. Kovrigin, Innovations in Agricultural Complex: Problems and Perspectives, Belgorod, Belgorod SAU, 4(12), 124-129 (2016)

7. A.V. Kovrigin, A.P. Khokhlova, and N.A. Maslova, Bulletin of KrasGAU, 11, 90-96, (2015)

8. A.V. Kovrigin, Applied computer programs in breeding and feeding, (Belgorod SAU, 2010)

9. A.V. Kovrigin, Collection of scientific works of the scientific school of professor G.S. Pokhodnya, 4, 48-49 (2011)

10. G.S. Pokhodnya, E.G. Fedorchuk, A.I. Grishin, R.A. Strelnikov, Vestnik of Kursk State Agricultural Academy. Kursk: Public house of Kursk State Agricultural Academy, 4, 47-48 (2012)

11. G.S. Pokhodnya, P.P. Kornienko, A.V. Kovrigin, Increase of the reproductive capacity of pigs, (Belgorod, Public house of Belgorod SAU, 2013)

12. G.S. Pokhodnya, N.I. Bogdanov, E.G. Fedorchuk, A.I Grishin., N.P. Dudina, Yu.P. Breslavets, Recommendations for the use of chlorella suspension in the diets of pigs, (Belgorod, 2012) 